Article

\title{
Fatty Acid Composition and Thermotropic Behavior of Glycolipids and Other Membrane Lipids of Ulva lactuca (Chlorophyta) Inhabiting Different Climatic Zones
}

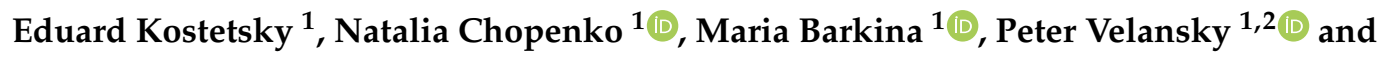 \\ Nina Sanina $1, * \mathbb{D}$ \\ 1 Department of Biochemistry, Microbiology and Biotechnology, School of Natural Sciences, \\ Far Eastern Federal University, Vladivostok 690091, Russia; kostetskiy.yeya@dvfu.ru (E.K.); \\ natali_1389@mail.ru (N.C.); marybarkin@yandex.ru (M.B.); velanskiy.pv@dvfu.ru (P.V.) \\ 2 National Scientific Center of Marine Biology, Far Eastern Branch of Russian Academy of Sciences, \\ Vladivostok 690041, Russia \\ * Correspondence: sanina.nm@dvfu.ru; Tel.: +7-423-265-2429
}

Received: 13 November 2018; Accepted: 5 December 2018; Published: 7 December 2018

\begin{abstract}
Increasing global temperatures are expected to increase the risk of extinction of various species due to acceleration in the pace of shifting climate zones. Nevertheless, there is no information on the physicochemical properties of membrane lipids that enable the adaptation of the algae to different climatic zones. The present work aimed to compare fatty acid composition and thermal transitions of membrane lipids from green macroalgae Ulva lactuca harvested in the Sea of Japan and the Adriatic Sea in summer. U. lactuca inhabiting the Adriatic Sea had bleached parts of thalli which were completely devoid of chloroplast glycolipids. The adaptation to a warmer climatic zone was also accompanied by a significant decrease in the ratio between unsaturated and saturated fatty acids (UFA/SFA) of membrane lipids, especially in bleached thalli. Hence, bleaching of algae is probably associated with the significant decrease of the UFA/SFA ratio in glycolipids. The decreasing ratio of $\mathrm{n}-3 / \mathrm{n}-6$ polyunsaturated fatty acids (PUFAs) was observed in extra-plastidial lipids and only in the major glycolipid, non-lamellar monogalactosyldiacylglycerol. The opposite thermotropic behavior of non-lamellar and lamellar glycolipids can contribute to maintenance of the highly dynamic structure of thylakoid membranes of algae in response to the increasing temperatures of climatic zones.
\end{abstract}

Keywords: glycolipids; phospholipids; betaine lipid; fatty acids; differential scanning calorimetry; thermal adaptation

\section{Introduction}

Over the last few decades, the temperature of seawaters has experienced changes that affect the Earth's ecological state on a global scale. Increasing global temperature is expected to increase the risk of extinction of various species in the future due to acceleration in the pace of shifting climate zones [1].

The primary interface between the environment and the organism's cells are the cell membranes, which are structurally based on the lipid matrix. The maintenance of the liquid crystalline state of the lipid matrix is necessary for the optimal functioning of biological membranes at different changes in the ambient temperature. Therefore, the primary effects of temperature, which is the most powerful environmental factor, are related to the compensatory molecular mechanisms directed to maintain the liquid crystalline state of the membrane lipid 
matrix [2,3]. This mechanism, which is called homeoviscous adaptation, is mainly realized due to rearrangements in the fatty acid composition of membrane lipids [4,5]. The efficiency of homeoviscous adaptation could be estimated by the lipid thermal transitions from a crystalline (gel) state to a liquid crystalline one. Our earlier studies on the fatty acid composition and phase transitions of the individual polar lipids from taxonomically different marine macrophytes inhabiting the Sea of Japan showed that the decrease in the ratio between unsaturated (UFA) and saturated fatty acids (SFA) was accompanied by the decrease in the ratio between n-3 and n- 6 polyunsaturated fatty acids (PUFAs) during acclimatization from winter to summer. Despite the larger changes of these ratios in photosynthetic lipids (glycolipids monogalactosyldiacylglycerol (MGDG), digalactosyldiacylglycerol (DGDG), sulfoquinovosyldiacylglycerol (SQDG) and phospholipid phosphatidyldiacylglycerol (PG)), peak maximum temperatures $\left(\mathrm{T}_{\max }\right)$ of their thermal transitions did not increase in contrast to the respective adaptive changes of non-photosynthetic phospholipids (phosphatidylcholine (PC)), (phosphatidylethanolamine) (PE)) and betaine lipid 1,2-diacylglycero-O-4'-(N,N,N-tri-methyl)-homoserine (DGTS) [6].

Extreme temperatures strongly affect the distribution of plants in the world. Ulva lactuca (Ulvales; Chlorophyta), widely known as U. fenestrata, is the most widespread edible green algae in the seas of all climatic zones. Nevertheless, there is no information on what features in physicochemical properties of membrane lipids facilitate the adaptation of the algae to the conditions of different climatic zones.

Moreover, abnormally high seawater temperatures could result in the partial or even total bleaching thalli of algae due to the loss of chlorophyll and other photosynthetic pigments that is accompanied by growth inhibition of plants $[7,8]$. However, the underlying mechanism and the role of the lipid matrix in these processes remain unknown.

Therefore, the aim of present work was to clarify the differences between the fatty acid composition and the thermotropic behavior of membrane lipids from $U$. lactuca adjusted to the conditions of different climatic zones - the Adriatic Sea (Mediterranean subtropical climatic zone) and the Sea of Japan (moderate climatic zone) as well as between green and bleached thalli of $U$. lactuca inhabiting the Adriatic Sea. The major membrane lipid of $U$. lactuca and other marine macrophytes MGDG is an important component of tubular immunostimulating complexes (TI-complexes) [9] that affect the conformation and immunogenicity of protein antigens [10,11]. Therefore, the results of the present work are also needed to modulate the lipid surrounding of subunit antigens incorporated in TI-complexes and to enhance their adjuvant effect.

\section{Results and Discussion}

To characterize differences in physicochemical properties of membrane lipids from U. lactuca adapted to the conditions of different climatic zones, glycolipids (MGDG, DGDG, SQDG) and the major phospholipids (PG and PE) [12] were isolated from algae harvested in the Adriatic Sea and the Sea of Japan in August, when the average seawater temperatures reach $26^{\circ} \mathrm{C}$ and $22{ }^{\circ} \mathrm{C}$, respectively. Betaine lipid DGTS which substitutes PC in green algae $[13,14]$ was also isolated from the algae.

Our earlier study has shown that the percentage of glycolipids, phospholipids and DGTS in $U$. lactuca harvested in the Sea of Japan in summer is $52 \%, 17 \%$ and $15 \%$ of total lipids without triacylglycerols, respectively. MGDG is the dominant glycolipid (37\% of total lipids without triacylglycerols), whereas the content of DGDG and SQDG is much less ( $10 \%$ and $5 \%$ of total lipids without triacylglycerols, respectively). Major phospholipids of $U$. lactuca are PG and PE (6\% and 3\% of total lipids without triacylglycerols, respectively). Lipid composition of $U$. lactuca is not highly dependent on season [15].

U. lactuca harvested in the Adriatic Sea had green and bleached parts of thalli (Figure 1). The last ones seem to appear due to the high-temperature stress, because the seawater temperature of $26^{\circ} \mathrm{C}$ and higher greatly inhibits the growth of $U$. lactuca [16]. This phenomenon is called thermal bleaching [7] because of the loss of chlorophyll and other pigments. The analysis of lipid composition has shown that bleached parts of the algal thalli were completely devoid of chloroplast-specific glycolipids, which are 
essential not only for the formation of lipid bilayers of chloroplast membranes, but also for embedding photosynthetic complexes in thylakoid membranes and as integral components of these complexes [17]. It was confirmed earlier that deficient synthesis of chloroplast-specific lipids in Arabidopsis mutants really results in a decrease of chlorophyll content, defects in chloroplast ultrastructure and reduced photosynthetic activity [18].

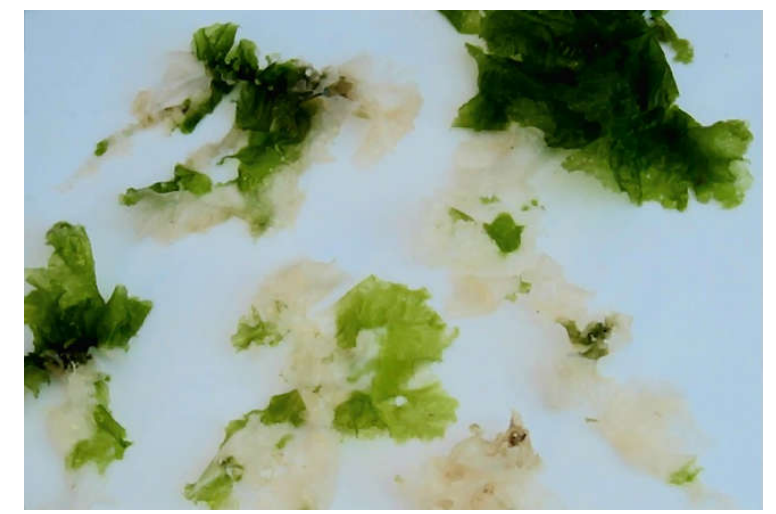

Figure 1. Green and bleached parts of thalli of Ulva lactuca harvested in the Adriatic Sea.

However, thermal bleaching parts of algae thalli contained extra-plastidial PE and DGTS as well PG, which not only plays a crucial role in the structure and function of photosynthetic complexes in thylakoid membranes but is also found in extra-plastidial membranes [19]. As such, cells of the bleaching parts were completely devoid of chloroplasts but retained extra-plastidial membranes and the ability to adjust them under conditions of heat stress, taking into account the adequate rearrangements in the fatty acid composition of PE, PG and DGTS (Tables 1 and 2).

Table 1. The fatty acid composition of phospholipids from green and bleached thalli of Ulva lactuca harvested in the Adriatic Sea and from green thalli of the same algae harvested in the Sea of Japan (\% of total fatty acids).

\begin{tabular}{ccccccc}
\hline \multirow{2}{*}{ Fatty Acids } & \multicolumn{3}{c}{ Phosphatidylglycerol } & \multicolumn{2}{c}{ Phosphatidylethanolamine } \\
\cline { 2 - 6 } & \multicolumn{2}{c}{ The Sea of Japan } & The Adriatic Sea & The Sea of Japan & The Adriatic Sea \\
\hline & \multicolumn{2}{c}{ Green Thalli } & Bleached Thalli & Green Thalli & Bleached Thalli \\
\hline $16: 0$ & $35.5 \pm 1.2$ & $45.2 \pm 0.8$ & $56.2 \pm 1.4$ & $22.0 \pm 0.6$ & $29.7 \pm 0.7$ & $56.2 \pm 1.3$ \\
$16: 1$ (n-7) & $0.9 \pm 0.1$ & $2.6 \pm 0.2$ & $2.1 \pm 0.1$ & $5.4 \pm 0.3$ & $4.4 \pm 0.2$ & $2.2 \pm 0.1$ \\
$16: 3$ (n-3) & $8.6 \pm 0.3$ & $0.6 \pm 0.1$ & $0.2 \pm 0.1$ & $0.4 \pm 0.1$ & $0.5 \pm 0.1$ & tr. \\
$16: 4$ (n-3) & $2.1 \pm 0.2$ & $0.8 \pm 0.1$ & $0.4 \pm 0.1$ & $0.7 \pm 0.1$ & $6.7 \pm 0.3$ & $0.9 \pm 0.1$ \\
$18: 0$ & $0.3 \pm 0.1$ & $0.5 \pm 0.1$ & $1.5 \pm 0.1$ & $4.6 \pm 0.3$ & $2.0 \pm 0.1$ & $2.8 \pm 0.2$ \\
$18: 1$ (n-9) & $0.6 \pm 0.1$ & $2.3 \pm 0.2$ & $2.8 \pm 0.2$ & $4.2 \pm 0.2$ & $3.4 \pm 0.2$ & $4.7 \pm 0.2$ \\
$18: 1$ (n-7) & $17.0 \pm 0.7$ & $19.6 \pm 0.5$ & $16.9 \pm 0.3$ & $10.5 \pm 0.8$ & $14.3 \pm 0.5$ & $18.7 \pm 0.3$ \\
$18: 2$ (n-6) & $2.3 \pm 0.2$ & $2.5 \pm 0.1$ & $1.4 \pm 0.1$ & $2.7 \pm 0.2$ & $5.8 \pm 0.4$ & $2.1 \pm 0.1$ \\
$18: 3$ (n-3) & $28.1 \pm 0.8$ & $14.1 \pm 0.3$ & $3.9 \pm 0.1$ & $26.2 \pm 0.5$ & $9.7 \pm 0.3$ & $2.5 \pm 0.1$ \\
$18: 4$ (n-3) & $1.9 \pm 0.1$ & $6.1 \pm 0.2$ & $2.0 \pm 0.1$ & $1.4 \pm 0.1$ & $9.8 \pm 0.2$ & $1.5 \pm 0.1$ \\
$22: 6$ (n-3) & tr. & $1.3 \pm 0.1$ & $0.9 \pm 0.1$ & $2.2 \pm 0.1$ & $4.5 \pm 0.1$ & $0.3 \pm 0.1$ \\
SFA & $36.4 \pm 1.0$ & $46.5 \pm 0.7$ & $60.7 \pm 0.5$ & $30.0 \pm 0.5$ & $34.6 \pm 0.5$ & $61.5 \pm 0.7$ \\
MUFA & $19.3 \pm 0.4$ & $25.5 \pm 0.6$ & $28.0 \pm 0.3$ & $24.0 \pm 0.4$ & $26.6 \pm 0.6$ & $29.2 \pm 0.4$ \\
PUFA & $44.3 \pm 0.3$ & $28.0 \pm 0.4$ & $11.3 \pm 0.3$ & $46.0 \pm 0.7$ & $38.8 \pm 0.4$ & $9.3 \pm 0.3$ \\
n-3/n-6 PUFA & $16.1 \pm 0.3$ & $6.5 \pm 0.2$ & $3.1 \pm 0.1$ & $9.9 \pm 0.2$ & $5.0 \pm 0.2$ & $1.9 \pm 0.1$ \\
UI & $152 \pm 2$ & $119 \pm 1$ & $66 \pm 1$ & $173 \pm 2$ & $183 \pm 2$ & $58 \pm 1$ \\
UFA/SFA & $1.7 \pm 0.1$ & $1.1 \pm 0.2$ & $0.6 \pm 0.1$ & $2.3 \pm 0.1$ & $1.9 \pm 0.1$ & $0.6 \pm 0.1$ \\
\hline
\end{tabular}

SFA, UFA, MUFA, PUFA—saturated, unsaturated, monounsaturated, polyunsaturated fatty acids, respectively; UI- unsaturation index. Fatty acids with content below $2 \%$ are excluded but considered in calculations of total values. tr.-traces (content less than $0.1 \%$ ). Mean values \pm standard error of triplicate determination. 
Table 2. The fatty acid composition of betaine lipid 1,2-diacylglycero-O-4'-( $N, N, N$-tri-methyl)-homoserine (DGTS) from green and bleached thalli of Ulva lactuca harvested in the Adriatic Sea and from green thalli of the algae harvested in the Sea of Japan (\% of total fatty acids).

\begin{tabular}{cccc}
\hline \multirow{2}{*}{ Fatty Acids } & The Sea of Japan & \multicolumn{2}{c}{ The Adriatic Sea } \\
\cline { 2 - 4 } & \multicolumn{2}{c}{ Green Thalli } & Bleached Thalli \\
\hline $14: 0$ & $0.4 \pm 0.1$ & $1.2 \pm 0.1$ & $2.3 \pm 0.1$ \\
$16: 0$ & $23.0 \pm 0.3$ & $31.0 \pm 0.2$ & $38.3 \pm 0.3$ \\
$16: 1(\mathrm{n}-9)$ & $0.4 \pm 0.1$ & $1.0 \pm 0.1$ & $4.3 \pm 0.2$ \\
$16: 1(\mathrm{n}-7)$ & $1.5 \pm 0.1$ & $5.8 \pm 2$ & $5.3 \pm 0.2$ \\
$18: 0$ & $0.8 \pm 0.1$ & $0.7 \pm 0.1$ & $0.7 \pm 0.1$ \\
$18: 1(\mathrm{n}-9)$ & $1.8 \pm 0.1$ & $1.8 \pm 0.1$ & $1.8 \pm 0.1$ \\
$18: 1(\mathrm{n}-7)$ & $9.9 \pm 0.2$ & $9.8 \pm 0.2$ & $9.8 \pm 0.2$ \\
$18: 2(\mathrm{n}-6)$ & $7.1 \pm 0.2$ & $2.2 \pm 0.1$ & $2.2 \pm 0.1$ \\
$18: 3(\mathrm{n}-6)$ & $4.5 \pm 0.1$ & $2.3 \pm 0.1$ & $2.3 \pm 0.1$ \\
$18: 3(\mathrm{n}-3)$ & $9.7 \pm 0.1$ & $6.6 \pm 0.2$ & $6.6 \pm 0.2$ \\
$18: 4(\mathrm{n}-3)$ & $28.2 \pm 0.1$ & $21.2 \pm 0.2$ & $21.2 \pm 0.2$ \\
$20: 5(\mathrm{n}-3)$ & $0.6 \pm 0.1$ & $3.0 \pm 0.1$ & $3.0 \pm 0.1$ \\
$22: 5(\mathrm{n}-3)$ & $7.1 \pm 0.2$ & $8.6 \pm 0.2$ & $8.6 \pm 0.2$ \\
SFA & $24.2 \pm 0.2$ & $34.2 \pm 0.2$ & $42.6 \pm 0.2$ \\
MUFA & $15.6 \pm 0.1$ & $18.0 \pm 0.2$ & $25.3 \pm 0.2$ \\
PUFA & $60.2 \pm 0.3$ & $47.8 \pm 0.1$ & $32.1 \pm 0.2$ \\
n-3/n-6 PUFA & $3.8 \pm 0.1$ & $5.8 \pm 0.1$ & $2.9 \pm 0.1$ \\
UI & $203 \pm 2$ & $195 \pm 1$ & $127 \pm 1$ \\
UFA/SFA & $3.1 \pm 0.1$ & $1.9 \pm 0.1$ & $1.3 \pm 0.1$ \\
\hline
\end{tabular}

SFA, UFA, MUFA, PUFA—saturated, unsaturated, monounsaturated, polyunsaturated fatty acids, respectively; UI- unsaturation index. Fatty acids with content below $2 \%$ are excluded but considered in calculations of total values. Mean values \pm standard error of triplicate determination.

\subsection{The Fatty Acid Composition of Phospholipids}

The fatty acid composition of major phospholipids isolated from $U$. lactuca is shown in Table 1. PG and PE from green thalli of algae inhabiting the Sea of Japan and the Adriatic Sea comprised the major fatty acid 16:0 with lesser amounts of 18:3 (n-3) and 18:1 (n-7). The first two fatty acids seem to play the main role in the adaptation of algae to different climatic zones, judging by the significant differences in their content in PG and PE from algae harvested in the Sea of Japan and the Adriatic Sea. However, the most profound changes occurred in bleached parts of algae from the Adriatic Sea. The content of PUFA 18:3 (n-3) was greatly reduced, whereas the level of 16:0 increased in the following line of the PG and PE sources: green algae from the Sea of Japan $\rightarrow$ green algae from the Adriatic Sea $\rightarrow$ bleached algae from the Adriatic Sea.

The percentage of 18:1 (n-7) in PE also increased in the same order. Especially pronounced changes occurred in total parameters of the fatty acid composition. The adaptation of U. lactuca to the higher temperature environment was accompanied by the essential increasing content of SFAs and monounsaturated fatty acids (MUFAs), as well as by decreasing percentage of PUFAs in PG and PE. Both phospholipids from bleached thalli were characterized by the prevailing content of SFAs and the lowest level of PUFAs and unsaturation index (UI). Simultaneously, the ratio of n-3/n-6 PUFAs consequently decreased, probably because of the increased demand for more potent mediators derived from n-6 PUFAs [20-22] in a warmer environment [6]. Then, changes in total parameters of the fatty acid composition observed in phospholipids from $U$. lactuca are mostly similar to earlier data on season acclimatization of marine macrophytes [6].

\subsection{The Fatty Acid Composition of Betaine Lipid 1,2-diacylglycero-O-4'-(N,N,N-tri-methyl)-homoserine (DGTS)}

The fatty acid composition of betaine lipid DGTS (Table 2) was somewhat different from that of phospholipids from U. lactuca (Table 1). It comprised the same major fatty acids: 16:0, 18:1 (n-7), 
18:3 (n-3). However, the dominant major UFA was 18:4 (n-3), which percentage was much lower in phospholipids. In addition, the percentage of 22:5 (n-3), which was absent in phospholipids, was considerable in DGTS. Similarly, to phospholipids, the level of SFAs (mostly 16:0) increased and the content of PUFAs (mostly 18:4 (n-3) and 18:3 (n-3)) decreased in the line of DGTS sources: green algae from the Sea of Japan $\rightarrow$ green algae from the Adriatic Sea $\rightarrow$ bleached algae from the Adriatic Sea. Unlike phospholipids, the level of MUFAs also increased in this line, although the dominant MUFA 18:1 (n-7) did not participate in the adaption process. Dissimilarity in the fatty acid compositions of DGTS and phospholipids was marked in other algae [23].

The mentioned changes were accompanied by a decrease in UI and ratios of UFA/SFA. However, the ratio of n-3/n-6 PUFAs decreased only in the bleached parts of the algae in comparison with green thalli.

\subsection{The Fatty Acid Composition of Glycolipids}

Glycolipids are the main components of photosynthetic membranes and associated with the functioning of the photosynthetic apparatus, whereas phospholipids, except PG, are mainly accumulated in non-photosynthetic membranes and differ from glycolipids by biosynthetic pathway [24]. Nevertheless, trends observed in the fatty acid composition of phospholipids and DGTS (Tables 1 and 2) also remained in glycolipids from U. lactuca (Table 3), which mainly contained the same fatty acids $(16: 0,16: 1$ (n-7), 18:1 (n-9), 18:1 (n-7), 18:2 (n-6), 18:3 (n-3) and 18:4 (n-3)) as well 16:3 (n-3) and 16:4 (n-3) found in phospholipids.

Table 3. The fatty acid composition of glycolipids from green parts of thalli of Ulva lactuca harvested in the Adriatic Sea and the Sea of Japan (\% of total fatty acids).

\begin{tabular}{|c|c|c|c|c|c|c|}
\hline \multirow{2}{*}{ Fatty Acids } & \multicolumn{2}{|c|}{ MGDG } & \multicolumn{2}{|c|}{ DGDG } & \multicolumn{2}{|c|}{ SQDG } \\
\hline & The Sea of Japan & $\begin{array}{c}\text { The } \\
\text { Adriatic Sea }\end{array}$ & The Sea of Japan & $\begin{array}{c}\text { The } \\
\text { Adriatic Sea }\end{array}$ & The Sea of Japan & $\begin{array}{c}\text { The } \\
\text { Adriatic Sea }\end{array}$ \\
\hline $16: 0$ & $2.8 \pm 0.1$ & $6.4 \pm 0.3$ & $22.2 \pm 0.3$ & $28.8 \pm 0.3$ & $56.7 \pm 0.4$ & $53.4 \pm 0.2$ \\
\hline $16: 1(n-7)$ & $0.8 \pm 0.1$ & $2.4 \pm 0.2$ & $0.7 \pm 0.1$ & $3.9 \pm 0.2$ & $1.5 \pm 0.1$ & $1.5 \pm 0.1$ \\
\hline $16: 2(n-6)$ & n.d. & n.d. & $7.8 \pm 0.2$ & $2.8 \pm 0.1$ & n.d. & n.d. \\
\hline $16: 3(n-3)$ & $3.0 \pm 0.2$ & $1.5 \pm 0.1$ & $8.3 \pm 0.2$ & $2.8 \pm 0.1$ & n.d. & tr. \\
\hline $16: 4(n-3)$ & $37.8 \pm 0.4$ & $32.3 \pm 0.4$ & $5.6 \pm 0.1$ & $1.5 \pm 0.1$ & n.d. & $0.3 \pm 0.1$ \\
\hline $18: 1(n-9)$ & $1.0 \pm 0.1$ & $2.3 \pm 0.1$ & $1.6 \pm 0.1$ & $4.4 \pm 0.1$ & $0.2 \pm 0.1$ & $0.2 \pm 0.1$ \\
\hline $18: 1(n-7)$ & $4.7 \pm 0.2$ & $7.0 \pm 0.5$ & $5.9 \pm 0.2$ & $12.5 \pm 0.2$ & $13.4 \pm 0.2$ & $22.1 \pm 0.3$ \\
\hline $16: 0$ & $2.8 \pm 0.1$ & $6.4 \pm 0.3$ & $22.2 \pm 0.3$ & $28.8 \pm 0.3$ & $56.7 \pm 0.4$ & $53.4 \pm 0.2$ \\
\hline $18: 2(n-6)$ & $1.5 \pm 0.1$ & $1.8 \pm 0.1$ & $11.8 \pm 0.3$ & $9.4 \pm 0.2$ & $3.5 \pm 0.1$ & $1.7 \pm 0.1$ \\
\hline $18: 3(n-3)$ & $18.5 \pm 0.3$ & $14.5 \pm 0.1$ & $30.4 \pm 0.5$ & $23.2 \pm 0.2$ & $23.6 \pm 0.3$ & $11.5 \pm 0.2$ \\
\hline $18: 4(n-3)$ & $25.7 \pm 0.4$ & $24.4 \pm 0.4$ & $3.5 \pm 0.2$ & $3.5 \pm 0.1$ & $1.6 \pm 0.1$ & $11.2 \pm 0.2$ \\
\hline $18: 2(n-6)$ & $1.5 \pm 0.1$ & $1.8 \pm 0.1$ & $11.8 \pm 0.3$ & $9.4 \pm 0.2$ & $3.5 \pm 0.1$ & $1.7 \pm 0.1$ \\
\hline SFA & $3.8 \pm 0.2$ & $7.0 \pm 0.3$ & $23.6 \pm 0.4$ & $31.8 \pm 0.3$ & $56.7 \pm 0.4$ & $53.7 \pm 0.3$ \\
\hline MUFA & $7.9 \pm 0.2$ & $13.2 \pm 0.3$ & $8.8 \pm 0.2$ & $21.6 \pm 0.4$ & $15.6 \pm 0.3$ & $23.0 \pm 0.3$ \\
\hline PUFA & $88.3 \pm 0.8$ & $79.8 \pm 0.9$ & $67.6 \pm 0.5$ & $46.6 \pm 0.7$ & $27.7 \pm 0.4$ & $23.3 \pm 0.3$ \\
\hline$n-3 / n-6$ PUFA & $50.7 \pm 0.3$ & $35.6 \pm 0.4$ & $2.5 \pm 0.2$ & $2.7 \pm 0.1$ & $7.2 \pm 0.2$ & $13.8 \pm 0.1$ \\
\hline UI & $334 \pm 3$ & $302 \pm 2$ & $203 \pm 2$ & $152 \pm 1$ & $89 \pm 1$ & $109 \pm 2$ \\
\hline UFA/SFA & $25.3 \pm 0.4$ & $13.3 \pm 0.2$ & $3.2 \pm 0.1$ & $2.1 \pm 0.1$ & $0.8 \pm 0.1$ & $0.9 \pm 0.1$ \\
\hline
\end{tabular}

SFA, UFA, MUFA, PUFA — saturated, unsaturated, monounsaturated, polyunsaturated fatty acids, respectively; UI-unsaturation index. Fatty acids with content below $2 \%$ are excluded but considered in calculations of total values. n.d.- - not detected, tr.- traces (content less than $0.1 \%$ ). Mean values \pm standard error of triplicate determination.

The greatest differences between glycolipids occurred in the composition of major fatty acids. The major fatty acids of MGDG were 16:4 (n-3), 18:4 (n-3), 18:3 (n-3), 18:1 (n-7), while DGDG mainly comprised 18:3 (n-3), 16:0, 18:2 (n-6) and 18:1 (n-7) in order of decreasing percentage. The major fatty acids of SQDG were similar to those of DGDG except for 18:2 (n-6), for which the percentage did not exceed $3.5 \%$.

However, SQDG from U. lactuca contained the highest level of cis-vaccenic acid 18:1 (n-7), which is not characteristic for other marine macrophytes [6,12]. Also, this glycolipid was the most enriched 
in SFA 16:0 (more than 50\% of total fatty acids) unlike MGDG where the percentage of 16:0 and SFAs as a whole was the lowest.

The adaption of $U$. lactuca to a warmer climatic zone was accompanied by the same changes in total parameters of the fatty acid composition in galactolipids, that was found in phospholipids and DGTS (Tables 1 and 2): the levels of SFAs and MUFAs increased, whereas other parameters (PUFAs, n-3/n-6 PUFAs, UI and UFA/SFA) decreased. This suggests that bleaching of $U$. lactuca has been accompanied by the strengthening of the trend found not only in extra-plastidial lipids, but also in chloroplast-specific glycolipids.

In SQDG, total parameters except MUFAs and PUFAs changed in the opposite way. The direction of changes in n-3/n-6 PUFAs of DGDG also did not coincide with the general trend.

The decline in the ratio of the UFA/SFA was greatest in MGDG, while SQDG had the smallest change. A decrease in the ratio of n-3/n-6 PUFAs was observed in MGDG only. However, this parameter increased or did not change in SQDG and DGDG, respectively. Perhaps the observed dissimilarity in the adaptive changes of the fatty acid composition may be the cause of different thermotropic behavior of glycolipids from U. lactuca harvested in the Adriatic Sea and the Sea of Japan (Figure 2).

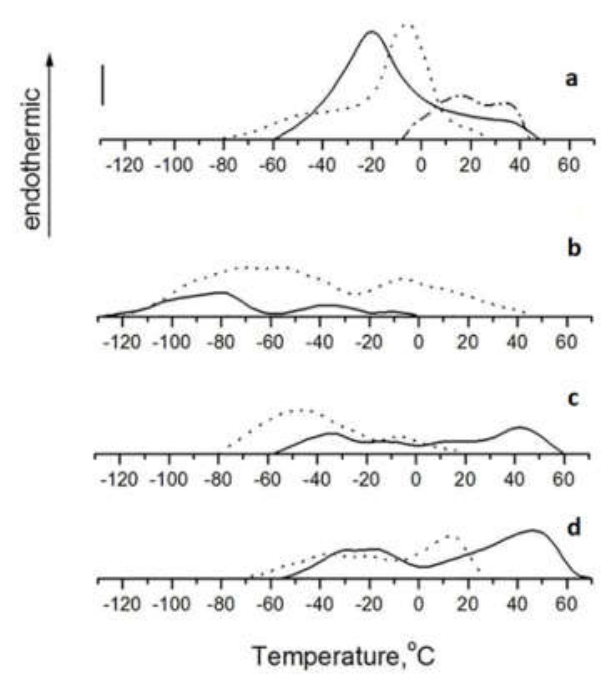

Figure 2. DSC thermograms of betaine lipid DGTS (a) and glycolipids MGDG (b), DGDG (c), SQDG (d) from the green thalli of Ulva lactuca inhabiting the Sea of Japan (solid curve), the green thalli of algae inhabiting the Adriatic Sea (dotted curve) and the bleached thalli of algae inhabiting the Adriatic Sea (dash-dotted curve). The vertical bar represents $0.5 \mathrm{~mW}$. The scanning rate, $16^{\circ} \mathrm{C} / \mathrm{min}$. The sample weight, $10 \mathrm{mg}$. Each sample was scanned at least three times.

\subsection{Thermotropic Behavior and Molecular Species of Polar Lipids}

Membrane lipid matrix of ectothermic organisms performs the role of thermosensor. The changes in the physical state of membrane lipids trigger compensatory adjustments in the fatty acid composition of membrane lipids directed to maintain the liquid crystalline state of the membrane lipid matrix, which is optimal for the functioning of living cells $[3,25,26]$. To assess the efficacy of adaptive rearrangements in the fatty acid composition of major polar lipids from $U$. lactuca, the thermotropic behavior of polar lipids was studied by differential scanning calorimetry (DSC). Calorimetry is the most appropriate method for a detection of the main lipid phase transition from crystalline to liquid crystalline state. Phase transitions of lipids occur due to trans-gauche rotational isomerization of methylene groups about the single $\mathrm{C}-\mathrm{C}$ bonds along lipid acyl chains. When lipid is heated, the heat flow difference between a sample and a reference is scanned in some temperature range. This endothermic process is visualized by DSC as an integral curve (thermogram) of dependence between a heat capacity and temperature. The peak maximum temperature of thermal transition $\left(\mathrm{T}_{\max }\right)$ is characteristic for a lipid 
sample of a definite chemical structure [27]. Additional peak(s) with lower heat capacity often occurred on thermograms of natural membrane lipids, which is probably due to their phase separation [28,29].

Thermograms and $\mathrm{T}_{\max }$ of thermal transitions of extra-plastidial betaine lipid DGTS and chloroplast-specific glycolipids MGDG, DGDG and SQDG of U. lactuca inhabiting the Sea of Japan and the Adriatic Sea are shown in Figure 2 and Table 4, respectively.

Table 4. Peak maximum temperatures of thermal transitions $\left(\mathrm{T}_{\max },{ }^{\circ} \mathrm{C}\right)$ of betaine lipid DGTS and glycolipids isolated from Ulva lactuca inhabiting the Sea of Japan and the Adriatic Sea.

\begin{tabular}{|c|c|c|}
\hline Lipids & & $\mathrm{T}_{\max },{ }^{\circ} \mathrm{C}^{1}$ \\
\hline \multirow{3}{*}{ DGTS } & Green thalli of $U$. lactuca inhabiting the Sea of Japan & -21 \\
\hline & Green thalli of $U$. lactuca inhabiting the Adriatic Sea & -6 \\
\hline & Bleached thalli of $U$. lactuca inhabiting the Adriatic Sea & 15 \\
\hline \multirow{2}{*}{ MGDG } & Green thalli of $U$. lactuca inhabiting the Sea of Japan & -78 \\
\hline & Green thalli of $U$. lactuca inhabiting the Adriatic Sea & -60 \\
\hline \multirow{2}{*}{ DGDG } & Green thalli of $U$. lactuca inhabiting the Sea of Japan & 41 \\
\hline & Green thalli of $U$. lactuca inhabiting the Adriatic Sea & -50 \\
\hline \multirow{2}{*}{ SQDG } & Green thalli of $U$. lactuca inhabiting the Sea of Japan & 50 \\
\hline & Green thalli of $U$. lactuca inhabiting the Adriatic Sea & 12 \\
\hline
\end{tabular}

Phase transition of DGTS from $U$. lactuca inhabiting the Sea of Japan was characterized by the cooperative endothermic peak at $-21^{\circ} \mathrm{C}$, which was lower by $15^{\circ} \mathrm{C}$ than $\mathrm{T}_{\max }$ of DGTS from U. lactuca inhabiting the Adriatic Sea (Figure 2A). Such a classical adaptive change in the thermotropic behavior is usual for non-photosynthetic phospholipids, especially for PC [6], that confirms functional similarity of DGTS and PC in extra-plastidial membranes. The increase in $\mathrm{T}_{\max }$ was accompanied by the 1.6-fold decrease in the ratio of UFA/SFA despite a little change in UI of the DGTS from U. lactuca inhabiting warmer climatic zone. Namely, the partial substitution (by 11.5\%) of highly unsaturated molecular forms MUFA/PUFA and PUFA/PUFA for SFA/MUFA and SFA/PUFA (Table 5) contributed to the increase of $\mathrm{T}_{\max }$.

The further rise in $\mathrm{T}_{\max }$ and the shift of the temperature range of the phase transition toward higher temperatures occurred at the thermal transition of DGTS from bleached thalli. The respective thermogram was located at the comparatively narrow temperature range between $-8{ }^{\circ} \mathrm{C}$ and $44{ }^{\circ} \mathrm{C}$ and characterized by two poorly resolved peaks at $15^{\circ} \mathrm{C}\left(\mathrm{T}_{\max }\right)$ and $35^{\circ} \mathrm{C}$. The cooperativity of phase transition significantly reduced likely due to the phase separation in this lipid sample. All changes in the thermotropic behavior of DGTS were accompanied by an increase in the share of SFA in its composition (Table 2).

Thermogram of MGDG from U. lactuca, harvested in the Sea of Japan lied in the temperature range between $-128{ }^{\circ} \mathrm{C}$ and $0{ }^{\circ} \mathrm{C}$. There were three peaks in this thermogram profile: the major peak at $-78{ }^{\circ} \mathrm{C}\left(\mathrm{T}_{\max }\right)$ and additional peaks with lower heat capacity at $-36{ }^{\circ} \mathrm{C}$ and $-10{ }^{\circ} \mathrm{C}$ (Figure $2 \mathrm{~B}$ ). MGDG from $U$. lactuca inhabiting the Adriatic Sea revealed the similar thermotropic behavior, while peaks of phase transition occurred at essentially higher temperatures (major peak at about $-60{ }^{\circ} \mathrm{C}$ and additional one at $-6{ }^{\circ} \mathrm{C}$ ). The high-temperature limit of phase transition was shifted to $44{ }^{\circ} \mathrm{C}$.

Nevertheless, $\mathrm{T}_{\text {max }}$ of MGDG remained very low. This can be explained by the high content of UFAs (more than $90 \%$ of total fatty acids) (Table 3). Most of them are represented by PUFAs (about $80-90 \%$ of total fatty acids). In turn, MGDG is the major factor responsible for the functioning of photosynthetic protein complexes. Hence, the high unsaturation probably allows MGDG to adopt different shapes of co-existing membrane protein complexes and stabilize them [5]. Highly unsaturated non-bilayer MGDG can also facilitate membrane deformation and provide the curvature matching of different proteins to the thylakoid membranes [30]. The increase in saturation of MGDG likely decreases the curvature in thylakoid membranes and promotes the crowding out of membrane proteins 
from the lipid bilayer that may disrupt the architecture and the functioning of thylakoid membranes. Therefore, MGDG plays a crucial role in the structural flexibility of lipid-light-harvesting complex II (LHCII) macro-assemblies. This lipid mediates the dimerization of photosystem II (PSII), as well as the packaging of PSII and photosystem I (PSI) [17,31]. Also, MGDG is structurally involved in the cytochrome b6/f complex [32] and activates the CF0-CF1-ATPase in chloroplasts [33].

Table 5. The composition of molecular species of betaine lipid DGTS and glycolipids from Ulva lactuca inhabiting the Sea of Japan and the Adriatic Sea (\% of the sum of molecular species).

\begin{tabular}{|c|c|c|c|c|c|c|c|c|}
\hline \multirow{2}{*}{$\begin{array}{l}\text { Molecular } \\
\text { Species }\end{array}$} & \multicolumn{2}{|c|}{ DGTS } & \multicolumn{2}{|c|}{ MGDG } & \multicolumn{2}{|c|}{ DGDG } & \multicolumn{2}{|c|}{ SQDG } \\
\hline & $\begin{array}{l}\text { The Sea } \\
\text { of Japan }\end{array}$ & $\begin{array}{c}\text { The Adriatic } \\
\text { Sea }\end{array}$ & $\begin{array}{l}\text { The Sea } \\
\text { of Japan }\end{array}$ & $\begin{array}{c}\text { The Adriatic } \\
\text { Sea }\end{array}$ & $\begin{array}{l}\text { The Sea } \\
\text { of Japan }\end{array}$ & $\begin{array}{c}\text { The Adriatic } \\
\text { Sea }\end{array}$ & $\begin{array}{l}\text { The Sea } \\
\text { of Japan }\end{array}$ & $\begin{array}{c}\text { The Adriatic } \\
\text { Sea }\end{array}$ \\
\hline $16: 0 / 16: 0$ & $0.5 \pm 0.1$ & $0.3 \pm 0.1$ & n.d. & tr. & $0.3 \pm 0.1$ & $1.4 \pm 0.1$ & $14.2 \pm 0.2$ & $4.3 \pm 0.2$ \\
\hline $14: 0 / 18: 1$ & n.d. & n.d. & tr. & $0.5 \pm 0.1$ & $0.9 \pm 0.1$ & $8.3 \pm 0.2$ & $2.3 \pm 0.1$ & $4.7 \pm 0.1$ \\
\hline $16: 0 / 16: 1$ & $3.1 \pm 0.1$ & $9.8 \pm 0.2$ & n.d. & n.d. & n.d. & n.d. & n.d. & n.d. \\
\hline $16: 0 / 18: 1$ & $1.5 \pm 0.1$ & $2.9 \pm 0.1$ & n.d. & $0.2 \pm 0.1$ & $5.8 \pm 0.2$ & $6.7 \pm 0.2$ & $23.5 \pm 0.3$ & $38.1 \pm 0.2$ \\
\hline $16: 0 / 18: 2$ & $6.6 \pm 0.2$ & $4.8 \pm 0.1$ & $2.3 \pm 0.1$ & $1.2 \pm 0.1$ & $19.7 \pm 0.2$ & $16.2 \pm 0.2$ & $6.7 \pm 0.2$ & $2.9 \pm 0.1$ \\
\hline $16: 0 / 22: 5$ & $4.5 \pm 0.2$ & $5.9 \pm 0.2$ & n.d. & n.d. & n.d. & n.d. & tr. & tr. \\
\hline $16: 1 / 18: 1$ & $1.2 \pm 0.1$ & $1.8 \pm 0.1$ & tr. & $0.2 \pm 0.1$ & $0.4 \pm 0.1$ & $4.6 \pm 0.2$ & tr. & $0.3 \pm 0.1$ \\
\hline $16: 1 / 18: 3$ & $1.9 \pm 0.1$ & $0.6 \pm 0.1$ & $2.6 \pm 0.2$ & $3.5 \pm 0.2$ & $1.9 \pm 0.1$ & $6.2 \pm 0.1$ & n.d. & tr. \\
\hline $16: 1 / 16: 4$ & tr. & $0.2 \pm 0.1$ & $0.7 \pm 0.1$ & $3.7 \pm 0.2$ & tr. & tr. & n.d. & n.d. \\
\hline $16: 1 / 18: 4$ & $1.6 \pm 0.1$ & $3.1 \pm 0.1$ & n.d. & $0.8 \pm 0.1$ & n.d. & tr. & n.d. & tr. \\
\hline $18: 1 / 16: 3$ & n.d & $0.4 \pm 0.1$ & $1.9 \pm 0.1$ & $1.5 \pm 0.1$ & $2.8 \pm 0.2$ & $2.9 \pm 0.1$ & tr. & tr. \\
\hline $16: 3 / 18: 3$ & $0.5 \pm 0.1$ & n.d. & $6.5 \pm 0.2$ & $4.0 \pm 0.2$ & $12.4 \pm 0.2$ & $2.1 \pm 0.1$ & tr. & tr. \\
\hline $16: 4 / 18: 4$ & $0.4 \pm 0.1$ & $0.2 \pm 0.1$ & $22.1 \pm 0.2$ & $27.8 \pm 0.2$ & $3.2 \pm 0.1$ & $1.1 \pm 0.1$ & n.d. & n.d. \\
\hline $18: 2 / 16: 4$ & $0.2 \pm 0.1$ & n.d. & $5.9 \pm 0.2$ & $3.6 \pm 0.2$ & $0.3 \pm 0.1$ & tr. & n.d. & n.d. \\
\hline $18: 3 / 18: 3$ & $1.6 \pm 0.1$ & $0.2 \pm 0.1$ & $1.6 \pm 0.1$ & $1.3 \pm 0.1$ & $3.7 \pm 0.2$ & $3.5 \pm 0.2$ & tr. & n.d. \\
\hline $18: 3 / 16: 4$ & $0.5 \pm 0.1$ & tr. & $30.1 \pm 0.2$ & $16.7 \pm 0.2$ & $5.4 \pm 0.1$ & $0.5 \pm 0.1$ & n.d. & n.d. \\
\hline $18: 3 / 18: 4$ & $4.3 \pm 0.1$ & $0.8 \pm 0.1$ & $1.2 \pm 0.1$ & $2.6 \pm 0.1$ & $0.6 \pm 0.1$ & $1.2 \pm 0.1$ & n.d. & n.d. \\
\hline $20: 5 / 22: 5$ & $3.8 \pm 0.1$ & $4.8 \pm 0.1$ & n.d. & n.d. & n.d. & n.d. & n.d. & n.d. \\
\hline SFA/SFA & $0.5 \pm 0.1$ & $0.3 \pm 0.1$ & tr. & tr. & $0.9 \pm 0.1$ & $1.4 \pm 0.1$ & $14.2 \pm 0.2$ & $4.9 \pm 0.2$ \\
\hline SFA/MUFA & $4.6 \pm 0.1$ & $12.7 \pm 0.2$ & tr. & $0.8 \pm 0.1$ & $6.8 \pm 0.1$ & $16.2 \pm 0.2$ & $26.2 \pm 0.2$ & $45.5 \pm 0.2$ \\
\hline SFA/PUFA & $50.9 \pm 0.2$ & $54.3 \pm 0.2$ & $7.6 \pm 0.2$ & $7.6 \pm 0.2$ & $39.6 \pm 0.2$ & $44.1 \pm 0.2$ & $58.9 \pm 0.2$ & $49.0 \pm 0.2$ \\
\hline MUFA/MUFA & $2.3 \pm 0.1$ & $2.7 \pm 0.1$ & tr. & $0.2 \pm 0.1$ & $0.6 \pm 0.1$ & $5.0 \pm 0.1$ & tr. & $0.3 \pm 0.1$ \\
\hline MUFA/PUFA & $24.7 \pm 0.2$ & $17.9 \pm 0.1$ & $15.8 \pm 0.3$ & $24.9 \pm 0.2$ & $10.3 \pm 0.2$ & $18.5 \pm 0.1$ & $0.3 \pm 0.1$ & $0.3 \pm 0.1$ \\
\hline PUFA/PUFA & $17.0 \pm 0.1$ & $12.1 \pm 0.1$ & $76.6 \pm 0.2$ & $66.5 \pm 0.2$ & $41.8 \pm 0.2$ & $14.8 \pm 0.1$ & $0.4 \pm 0.1$ & tr. \\
\hline
\end{tabular}

Molecular species with content lower $2 \%$ are excluded, but considered in calculations of total values. SFA, MUFA, PUFA — saturated, monounsaturated, polyunsaturated fatty acid, respectively. n.d.—not detected, tr.-traces (content less than $0.1 \%$ ). Mean values \pm standard error of triplicate determination.

From the point of view of homeoviscous adaptation, the shift of $\mathrm{T}_{\max }$ to the higher temperatures is the adequate compensatory adjustment, which was provided by the classical decrease in the unsaturation of fatty acids in MGDG. The same changes in the fatty acid composition as well as decreasing n-3/n-6 PUFAs of this glycolipid from $U$. lactuca and other marine macrophytes were observed at the season change from winter to summer [6]. As shown in Table 5, the following major molecular species of MGDGs likely contributed to the formation of the major peak on the respective thermograms: 18:3/16:4, 16:4/18:4, as well as 18:1/16:4, 16:3/18:3, 16:2/18:3 and 18:2/16:4 whose sum was about $70 \%$. The positional distribution of fatty acids within MGDG from algae depends on the fatty acid chain length rather than on their unsaturation degree. The preferential occurrence of $18 \mathrm{C}$ and 16C fatty acid residues in sn-1 and sn-2 positions of the glycerol backbone of MGDG, respectively, is typical for green algae [34]. Higher $\mathrm{T}_{\max }$ of MGDG from algae inhabiting warmer climatic zone was probably due to the two-fold lower content of major molecular species 18:3/16:4.

In spite of the lowering ratio of UFA/SFA, $\mathrm{T}_{\max }$ of lamellar DGDG decreased, in contrast to non-lamellar MGDG (Figure 2B). An especially remarkable change occurred in the percentage of MUFAs in DGDG (by the 2.5-fold increase) which reduces phase transition temperature more effectively than PUFAs with three or more double bonds $[35,36]$ (Table 3). MUFAs were situated in the following molecular species of DGDG: 14:0/18:1, 16:1/18:1 and 16:1/18:3, whose total content was six-fold higher in DGDG from algae inhabiting the Adriatic Sea in comparison with DGDG from algae inhabiting the 
Sea of Japan (Table 5). The total indicators (MUFA/PUFA and MUFA/MUFA) also demonstrated the major contribution of the DGDG molecular species containing MUFAs to the lowering of $T_{\max }$. In turn, the sharp decrease in the level of highly unsaturated molecular species PUFA/PUFA probably does not effectively influence the thermotropic behavior of DGDG.

Adaptive changes in phase transition of SQDG was similar to that of DGDG (Figure 2C,D, respectively) in spite of essentially different polar groups and the fatty acid composition of these glycolipids. As such, a set of major molecular species of SQDG comprises 16:0/18:3, 16:0/18:1, 16:0/16:0, 16:0/18:4 (Table 5), while highly unsaturated molecular species MUFA/PUFA and PUFA/MUFA, whose high content was detected in DGDG, practically absent in SQDG. As a whole, SQDG is the most saturated glycolipid. Therefore, $\mathrm{T}_{\max }$ of SQDG is the highest in comparison with $\mathrm{T}_{\max }$ of other glycolipids from $U$. lactuca regardless of the temperature conditions of the habitat of the algae. The shift of $\mathrm{T}_{\max }$ of SQDG from $U$. lactuca depending on climatic zones was not as sharp as it was found to be for DGDG (about $60^{\circ} \mathrm{C}$ against about $90^{\circ} \mathrm{C}$, respectively) (Figure 2C,D, respectively), which was accompanied by a less pronounced increase in the level of MUFAs. The lower $\mathrm{T}_{\max }$ of SQDG from U. lactuca inhabiting warmer climatic zone also correlated with a threefold lower level of the most high-melting molecular species SFA/SFA, as well as remarkably higher UI and UFA/SFA.

Homeoviscous adaptation is the compensatory mechanism that allows cell membranes to maintain the functionally optimal viscosity and, hence, the integrity of organelles at different environmental temperatures [5]. The infringement of the thylakoid membrane integrity initiates the bleaching of algae at elevated temperatures [7]. Our results on the fatty acid composition of PG, PE and DGTS of bleached parts of $U$. lactuca (Tables 1-3) allow us to propose that elevated ambient temperature also induces the significant increase of the fatty acid saturation in the major chloroplast glycolipids and the following destruction of thylakoid membranes, the release of glycolipids and chlorophyll [18].

Opposite changes in the thermotropic behavior of non-lamellar MGDG and lamellar DGDG and SCDG probably maintain the highly dynamic structure of the $U$. lactuca thylakoid membranes in response to an increase in temperature of climatic zones. Therefore, a highly dynamic flexibility of the thylakoid structure can be supported by the fine tuning of MGDG/DGDG ratio which influences the reversible transitions between non-lamellar and lamellar phases in thylakoid lipids [37]. As shown earlier [15], the MGDG/DGDG ratio increases at warm-acclimatization of $U$. lactuca. To compensate for the destabilizing effect of the MGDG elevated level at the adaptation of algae to warmer climatic zone, $\mathrm{T}_{\max }$ of this glycolipid increased. Instead, the lowering of the DGDG share was accompanied by the decrease of its $\mathrm{T}_{\max }$.

On the other hand, the hydrogen bonds between the DGDG polar heads of adjacent bilayers result in thylakoid membrane stacking. However, electrostatic repulsion between positively charged molecules of SQDG hinders the stacking of thylakoid membranes, which additionally contributes to the dynamic structure of the thylakoid grana [37]. Probably, another way to maintain the highly dynamic structure of the thylakoid membranes is the decrease of the $T_{\max }$ and possibly the level [6] of SQDG from $U$. lactuca inhabiting the warmer climate zone.

The pronounced phase separation, which is characteristic for the thermotropic behavior of all glycolipids may provide a different lipid environment for PSI and PSII segregated into stroma and grana thylakoid membranes, respectively [38]. The higher mobility of protein complexes in stroma thylakoids indirectly confirms our assumption [39].

\section{Materials and Methods}

\subsection{Plants}

Marine macroalgae $U$. lactuca (Chlorophyta: Ulvales) was harvested in the Peter the Great Gulf of the Sea of Japan (moderate climatic zone) in August at seawater temperature of $24{ }^{\circ} \mathrm{C}$, seawater salinity of $34.5 \%$, at a depth of about $1.5 \mathrm{~m}$, and in the Adriatic Sea near the western coast of the Istrian peninsula (subtropical climatic zone) in August at seawater temperature of $27^{\circ} \mathrm{C}$, seawater salinity of 
$36 \%$, at a depth of about $1.5 \mathrm{~m}$. The anatomical and morphological analysis of thalli of the algae was performed with the Axio Imager light microscope (Carl Zeiss, Oberkochen, Germany). In each case the investigated thalli were in a sterile state, without signs of reproduction [40]. Live algal biomass was collected per $500 \mathrm{~g}$ from each place. Adriatic algae had bleached parts of thalli, which were separated from green parts of thalli. Freshly harvested algae were thoroughly cleaned to remove epiphytes, small invertebrates and sand particles, and then heated for 2 minutes in boiling $\mathrm{H}_{2} \mathrm{O}$ to inactivate enzymes.

\subsection{Extraction and Isolation of Lipids}

Total lipids were extracted from algae by the method of Bligh and Dyer [41]. Crude glycoand phospholipids were isolated from total lipid extract by column chromatography on silica gel by elution with acetone, acetone/benzene/acetic acid/water (200:30:3:10, by vol.) and a gradient of chloroform and methanol, respectively [6]. Betaine lipid DGTS was eluted with chloroform/methanol/benzene/ $28 \%$ aqueous ammonia (65:30:10:6, by vol.). Then, these lipids were purified by preparative silica thin-layer chromatography (TLC) using acetone/benzene/acetic acid/water (200:30:3:10, by vol.) or chloroform/methanol/water (65:25:4, by vol.), respectively. The purity of lipids was checked by two-dimensional silica TLC [42,43].

\subsection{Analysis of the FattyAcid Composition}

The fatty acid composition of chromatographically pure lipids was studied by gas-liquid chromatography as described earlier [6]. Esterification of lipids was performed with acetylchloride/methanol (1:20) at $95^{\circ} \mathrm{C}$ for $1 \mathrm{~h}$. Fatty acid methyl esters were extracted with $n$-hexane and purified by TLC. Analysis of fatty acid methyl esters was performed by an Agilent 6898 gas chromatograph (Agilent Technologies, Santa Clara, USA), equipped with a flame-ionization detector, a silica capillary column $(25 \mathrm{~m} \times 0.25 \mathrm{~mm})$ with Carbowax $20 \mathrm{M}$. The carrier gas was helium. Individual peaks of fatty acid methyl esters were identified by comparison of GC $R_{\mathrm{t}} \mathrm{S}$ with those of authentic standards of fatty acid methyl esters and by equivalent chain length (ECL). Statistical analysis was carried out using the program Microsoft Excel. The results are presented as mean values \pm standard error of triplicate determination.

\subsection{Calorimetry}

The thermotropic behavior of chromatographically pure lipids was studied by differential scanning calorimetry as described earlier [6]. Lipids solubilized in chloroform were introduced into standard aluminum pans. Vacuum dried samples of approximately $10 \mathrm{mg}$ were sealed into pans and placed in a DSC-2M differential scanning calorimeter (Biopribor, Puschino, Russia). Samples were either heated or cooled at $16^{\circ} \mathrm{C}$ min between $-135^{\circ} \mathrm{C}$ and $80^{\circ} \mathrm{C}$ at a sensitivity of $5 \mathrm{~mW}$. The position of the maximum of heat capacity vs. temperature plot was recorded as the phase transition temperature, $\mathrm{T}_{\max }$. The temperature range was calibrated by naphthalene, mercury and indium.

\subsection{Analysis of the Molecular Species Composition}

Analytical separation of molecular species of lipids was performed by high-performance liquid chromatography (HPLC) on chromatograph Shimadzu-LC20 with mass-detector LCMS-2010EV (Shimadzu Corp., Duisburg, Germany). It was used Ascentis C18 column (Supelco, Bellefonte, PA, USA), $25 \mathrm{~cm} \times 2.1 \mathrm{~mm}, 5 \mu \mathrm{m}$ particle size. The column was thermostated at a temperature of $45{ }^{\circ} \mathrm{C}$. The flow rate was of $0.3 \mathrm{~mL} / \mathrm{min}$. Intervals with the constant eluent composition $(5 \mathrm{mM}$ aqueous solution of ammonium acetate/methanol/isopropanol, $\mathrm{v} / \mathrm{v}$ ) were following: $0 \mathrm{~min}-6: 92: 2$, 30 min $6: 79: 15,35-38$ min—6:69:25 for MGDG, DGDG, SQDG; 0 min $6: 92: 2,45$ min $-6: 86: 8$, 50-65 min—6:54:40 for DGTS. Mass-detector's options: electrospray ionization, positive ion detection mode for MGDG, DGDG and DGTS, negative ion—for SQDG; nitrogen flow- $1.5 \mathrm{~L} / \mathrm{min}$; voltage of capillary- $4.5 \mathrm{kV}$ for positive ionization, $3.5 \mathrm{kV}$ for negative ionization; temperature of line of desolvation $-250{ }^{\circ} \mathrm{C}$; temperature of input interface $-280^{\circ} \mathrm{C}$. The content of molecular species was 
determined by the peak areas on chromatograms of quasimolecular ions corresponding to each molecular species; sn-positions of acyls in lipid structure were not defined [44].

Statistical analysis was carried out using the program Microsoft Excel. The results are presented in the form of mean value \pm standard error of triplicate determination.

\section{Conclusions}

The comparison of adaptive changes in the fatty acid composition and thermal transitions of polar lipids of $U$. lactuca allowed us to simulate the situation that is expected due to acceleration in the pace of shifting climate zones. Heat stress was shown to induce an intensified decline in the ratio of UFA/SFA in polar lipids of bleached parts of algal thalli, which is an adequate response from the point of view of the theory of homeoviscous adaptation. However, this process has a flip side. A significant increase in the share of SFA in chloroplast-specific non-bilayer MGDG likely decreases the curvature in thylakoid membranes and promotes the crowding out of different membrane proteins, participating in photosynthesis, from the lipid bilayer that may disrupt the architecture and the functioning of thylakoid membranes and chloroplasts as a whole. The opposite changes in the thermotropic behavior of non-lamellar MGDG and lamellar DGDG and SQDG, are probably directed to maintain a highly dynamic structure of thylakoid membranes of $U$. lactuca in response to increasing temperature of climatic zones. Despite the loss of glycolipids and, therefore, chloroplast membranes at heat stress, lipids of extra-plastidial membranes and other likely related functions exhibit thermotolerance, which can only prolong the life of $U$. lactuca and possibly of other algae in conditions of shifting climatic zones due to the increasing global temperature.

Author Contributions: conceptualization, E.K. and N.S.; methodology, N.S. and P.V.; software, M.B.; formal analysis, N.S., E.K., M.B., P.V. and N.C.; investigation, N.C., M.B. and P.V.; resources, E.K.; data curation, M.B.; writing, N.S., M.B., N.C. and E.K.; visualization, M.B.; supervision, N.S.; project administration, E.K.; funding acquisition, E.K. and N.S.

Funding: This research was funded by the Russian Science Foundation, grant number 15-15-00035-P and Ministry of Education and Science of the Russian Federation, the state assignment number 6.5736.2017/6.7.

Acknowledgments: Research described in this publication was supported in part concerned the harvesting, extraction, isolation, thermotropic behavior of lipids of $U$. lactuca by the Russian Science Foundation (project 15-15-00035-P). The part concerned with analysis of the fatty acid composition and molecular species of lipids from U. lactuca was supported by Ministry of Education and Science of the Russian Federation within the state assignment No.6.5736.2017/6.7.

Conflicts of Interest: The authors declare no conflict of interest.

\section{References}

1. Mahlstein, I.; Daniel, J.S.; Solomon, S. Pace of shifts in climate regions increases with global temperature. Nature Clim. Chang. 2013, 3, 739-743. [CrossRef]

2. Beney, L.; Gervais, P. Influence of the fluidity of the membrane on the response of microorganisms to environmental stresses. Appl. Microbiol. Biotechnol. 2001, 57, 34-42. [PubMed]

3. Török, Z.; Tsvetkova, N.M.; Balogh, G.; Horváth, I.; Nagy, E.; Pénzes, Z.; Hargitai, J.; Bensaude, O.; Csermely, P.; Crowe, J.H.; et al. Heat shock protein coinducers with no effect on protein denaturation specifically modulate the membrane lipid phase. Proc. Natl. Acad. Sci. USA 2003, 100, 3131-3136. [CrossRef] [PubMed]

4. Sinensky, M. Homeoviscous adaptation-A homeostatic process that regulates the viscosity of membrane lipids in Escherichia coli. Proc. Natl. Acad. Sci. USA 1974, 71, 522-525. [CrossRef] [PubMed]

5. Ernst, R.; Ejsing, C.S.; Antonny, B. Homeoviscous adaptation and the regulation of membrane lipids. J. Mol. Biol. 2016, 428, 4776-4791. [CrossRef] [PubMed]

6. Sanina, N.M.; Goncharova, S.N.; Kostetsky, E.Y. Seasonal change of fatty acid composition and thermotropic behavior of polar lipids marine macrophytes. Phytochemistry 2008, 69, 1517-1527. [CrossRef] [PubMed] 
7. Tchernov, D.; Gorbunov, M.Y.; de Vargas, C.; Narayan Yadav, S.; Milligan, A.; Haggblom, M.; Falkowski, P. Membrane lipids of symbiotic algae are diagnostic of sensitivity to thermal bleaching in corals. Proc. Natl. Acad. Sci. USA 2004, 101, 13531-13535. [CrossRef] [PubMed]

8. De Silva, H.C.C.; Asaeda, T. Effects of heat stress on growth, photosynthetic pigments, oxidative damage and competitive capacity of three submerged macrophytes. J. Plant Interact. 2017, 12, 228-236. [CrossRef]

9. Kostetsky, E.Y.; Sanina, N.M.; Mazeika, A.N.; Tsybulsky, A.V.; Vorobyeva, N.S.; Shnyrov, V.L. Tubular immunostimulating complex based on cucumarioside A2-2 and monogalactosyldiacylglycerol from marine macrophytes. J. Nanobiotechnol. 2011, 9, 9-35. [CrossRef]

10. Sanina, N.M.; Kostetsky, E.Y.; Shnyrov, V.L.; Tsybulsky, A.V.; Novikova, O.D.; Portniagina, O.Y.; Vorobieva, N.S.; Mazeika, A.N.; Bogdanov, M.V. The influence of monogalactosyldiacylglycerols from different marine macrophytes on immunogenicity and conformation of protein antigen of tubular immunostimulating complex. Biochimie 2012, 94, 1048-1056. [CrossRef]

11. Sanina, N.; Davydova, L.; Chopenko, N.; Kostetsky, E.; Shnyrov, V. Modulation of immunogenicity and conformation of HA1 subunit of influenza A virus H1/N1 hemagglutinin in tubular immunostimulating complexes. Int. J. Mol. Sci. 2017, 18, E1895. [CrossRef] [PubMed]

12. Sanina, N.M.; Goncharova, S.N.; Kostetsky, E.Y. Fatty acid composition of individual polar lipid classes from marine macrophytes. Phytochemistry 2004, 65, 721-730. [CrossRef]

13. Dembitsky, V.M.; Rozentsvet, O.A. Diacylgliceryltrimethylhomoserines and phospholipids of some marine macrophytes. Phytochemistry 1989, 28, 3341-3343. [CrossRef]

14. Van Ginneken, V.; Gittenberger, A.; Rensing, M.; de Vries, E.; Peeters, E.T.H.M.; Verheij, E. Seaweed

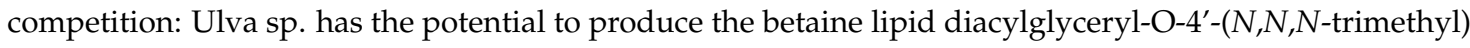
homoserine (DGTS) in order to replace phosphatidylcholine (PC) under phosphate-limiting conditions in the P-limited Dutch Wadden Sea and outcompete an Aggressive non-indigenous Gracilaria vermiculophylla red drift algae out of this Unique Unesco world heritage coastal area. Ocean E Fish Open Access J. 2017, 2, 555596. [CrossRef]

15. Kostetsky, E.Y.; Goncharova, S.N.; Sanina, N.M.; Shnyrov, V.L. Season influence on lipid composition of marine macrophytes. Bot. Mar. 2004, 47, 134-139. [CrossRef]

16. Kalita, T.L.; Tytlianov, E.A. Effect of temperature and illumination on growth and reproduction of the green alga Ulva fenestrata. Russ. J. Mar. Biol. 2003, 29, 316-322. [CrossRef]

17. Kobayashi, K.; Endo, K.; Wada, H. Roles of lipids in photosynthesis. In Lipids in Plant and Algae Development; Subcell, B., Nakamura, Y., Li-Beisson, Y., Eds.; Springer International Publishing: Basel, Switzerland, 2016; Volume 86, pp. 21-50, ISBN 978-3-319-25979-6.

18. Wang, Z.; Benning, C. Chloroplast lipid synthesis and lipid trafficking through ER-plastid membrane contact sites. Biochem. Soc. Trans. 2012, 40, 457-463. [CrossRef]

19. Zhou, Y.; Hölzl, G.; vom Dorp, K.; Peisker, H.; Melzer, M.; Frentzen, M.; Dörmann, P. Identification and characterization of a plastidial phosphatidylglycerophosphate phosphatase in Arabidopsis thaliana. Plant J. 2017, 89, 221-234. [CrossRef] [PubMed]

20. Lauritzen, L.; Hansen, H.S.; Jorgesen, M.H.; Michaelsen, K.F. The essentiality of long chains n-3 fatty acids in relation to development and function of the brain and retina. Prog. Lipid Res. 2001, 40, 1-94. [CrossRef]

21. Bagga, D.; Wang, L.; Farias-Eisner, R.; Glaspy, J.A.; Reddy, S.T. Differential effects of prostaglandin derived from $\omega-6$ and $\omega-3$ polyunsaturated fatty acids on COX-2 expression and IL-6 secretion. Proc. Natl. Acad. Sci. USA 2003, 100, 1751-1756. [CrossRef] [PubMed]

22. Calder, P.C. n-3 Polyunsaturated fatty acids, inflammation, and inflammatory diseases. Am. J. Clin. Nutr. 2006, 83, 1505-1519. [CrossRef] [PubMed]

23. Weber, N.; Bergenthal, D.; Kokate, C.K.; Mangold, H.K. Biologically active ether lipids: incorporation of long-chain precursors into 1(3),2-diacylglycero-3(1)-O-4'-(N,N,N-trimethyl)homoserines and other lipids of Chlorella fusca. J. Lipid Mediat. 1989, 1, 37-48. [PubMed]

24. Kalisch, B.; Dörmann, P.; Hölzl, G. DGDG and glycolipids in plants and algae. In Lipids in Plant and Algae Development; Subcell, B., Nakamura, Y., Li-Beisson, Y., Eds.; Springer International Publishing: Basel, Switzerland, 2016; Volume 86, pp. 51-84, ISBN 978-3-319-25979-6.

25. Gombos, Z.; Wada, H.; Murata, N. The recovery of photosynthesis from low-temperature photoinhibition is accelerated by the unsaturation of membrane lipids: a mechanism of chilling tolerance. Proc. Natl. Acad. Sci. USA 1994, 91, 8787-8791. [CrossRef] 
26. Vigh, L.; Nakamoto, H.; Landry, J.; Gomez-Munos, A.; Harwood, J.L.; Horvath, I. Membrane regulation of the stress response from prokaryotic models to mammalian cells. Ann. N. Y. Acad. Sci. 2007, 1113, 40-51. [CrossRef] [PubMed]

27. Huang, C.-H.; Li, S. Calorimetric and molecular mechanics studies of the thermotropic phase behavior of membrane phospholipids. Biochim. Biophys. Acta 1999, 1422, 273-307. [CrossRef]

28. Raison, J.K.; Wright, L.C. Thermal phase-transitions in the polar lipids of plant membranes-Their induction by desaturated phospholipids and their possible relation to chilling injury. Biochim. Biophys. Acta 1983, 731, 69-78. [CrossRef]

29. Welti, R.; Glaser, M. Lipid domains in model and biological membranes. Chem. Phys. Lipids 1994, 73, 121-137. [CrossRef]

30. Brown, M.F. Curvature forces in membrane lipid-protein interactions. Biochemistry 2012, 51, 9782-9795. [CrossRef]

31. Garab, G.; Ughy, B.; Goss, R. Role of MGDG and non-bilayer lipid phases in the structure and dynamics of chloroplast thylakoid membranes. In Lipids in Plant and Algae Development; Subcell, B., Nakamura, Y., Li-Beisson, Y., Eds.; Springer International Publishing: Basel, Switzerland, 2016; Volume 86, pp. 127-157, ISBN 978-3-319-25979-6.

32. Georgiev, G.A.; Ivanova, S.; Jordanova, A.; Tsanova, A.; Getov, V.; Dimitrov, M.; Lalchev, Z. Interaction of monogalactosyldiacylglycerol with cytochrome b6f complex in surface films. Biochem. Biophys. Res. Commun. 2012, 419, 648-651. [CrossRef]

33. Joyard, J.; Teyssier, E.; Miège, C.; Seigneurin-Berny, D.; Maréchal, E.; Block, M.; Dorne, A.-J.; Rolland, N.; Ajlani, G.; Douce, R. The biochemical machinery of plastid envelope membranes. Plant Physiol. 1998, 118, 715-723. [CrossRef]

34. Arao, T.; Yamada, M. Positional distribution of fatty acids in galactolipids of algae. Phytochemistry 1989, 28, 805-810. [CrossRef]

35. Keough, K.M.W.; Giffin, B.; Kariel, N. The influence of unsaturation on the phase transition temperatures of a series of heteroacid phosphatidylcholines containing twenty-carbon chains. Biochim. Biophys. Acta 1987, 902, 1-10. [CrossRef]

36. Kostetsky, E.Y.; Sanina, N.M.; Naumenko, N.V. The influence of fatty acid composition on the profile of the phase transition thermogram of phosphatidylcholine from holothurians Cucumaria fraudatrix. Zh. Evol. Biochem. Physiol. 1992, 28, 426-433.

37. Demé, B.; Cataye, C.; Block, M.A.; Maréchal, E.; Jouhet, J. Contribution of galactoglycerolipids to the 3-dimensional architecture of thylakoids. FASEB J. 2014, 28, 3373-3383. [CrossRef] [PubMed]

38. Austin, J.R.; Staehelin, A.L. Three-dimensional architecture of grana and stroma thylakoids of higher plants as determined by electron tomography. Plant Physiol. 2011, 155, 1601-1611. [CrossRef] [PubMed]

39. Kirchhoff, H.; Sharpe, R.M.; Herbstova, M.; Yarbrough, R.; Edwards, G.E. Differential mobility of pigment-protein complexes in granal and agranal thylakoid membranes of $\mathrm{C}_{3}$ and $\mathrm{C}_{4}$ plants. Plant Physiol. 2013, 161, 497-507. [CrossRef] [PubMed]

40. Vinogradova, K.L. Manual of Algae of Far Eastern Seas of the USSR. Green Algae; Nauka: Leningrad, Russia, 1979; pp. 46-110.

41. Bligh, E.G.; Dyer, W.I. A rapid method of total lipid extraction and purification. Canad. J. Biochem. Physiol. 1959, 37, 911-918. [CrossRef] [PubMed]

42. Vaskovsky, V.E.; Terekhova, T.A. HPTLC of phospholipids mixtures containing phosphatidylglycerol. J. High Resolut. Chromatogr. 1979, 2, 671-672. [CrossRef]

43. Vaskovsky, V.E.; Khotimchenko, S.V. HPTLC of polar lipids of algae and other plants. J. Chromatogr. 1982, 5, 635-636. [CrossRef]

44. Kostetsky, E.Y.; Velansky, P.V.; Sanina, N.M. Phase transition of phospholipids as criterion for assessing the capacity for thermal adaptation in fish. Russ. J. Mar. Biol. 2013, 39, 136-143. [CrossRef]

(C) 2018 by the authors. Licensee MDPI, Basel, Switzerland. This article is an open access article distributed under the terms and conditions of the Creative Commons Attribution (CC BY) license (http:/ / creativecommons.org/licenses/by/4.0/). 